\title{
Assessing the Impact of a Vinasse Pilot Plant Scale-Up on the Key Processes of the Ethanol Supply Chain
}

\author{
Rocio Ramos-Hernández, ${ }^{1}$ Dulce Rocio Mota-López, ${ }^{1}$ Cuauhtémoc Sánchez-Ramírez, ${ }^{1}$ \\ Giner Alor-Hernández, ${ }^{1}$ Jorge Luis García-Alcaraz, ${ }^{2}$ and Galo Rafael Urrea-García ${ }^{1}$ \\ ${ }^{1}$ Division of Research and Postgraduate Studies, Instituto Tecnológico de Orizaba, Avenida Oriente 9, 852 Colonia Emiliano Zapata, \\ 94320 Orizaba, VER, Mexico \\ ${ }^{2}$ Department of Industrial and Manufacturing Engineering, Universidad Autónoma de Ciudad Juárez, Avenida del Charro, 450 Norte, \\ Colonia Partido Romero, 32310 Ciudad Juárez, CHIH, Mexico
}

Correspondence should be addressed to Cuauhtémoc Sánchez-Ramírez; cuauhtemoc.sanchezr@gmail.com

Received 21 May 2016; Accepted 17 July 2016

Academic Editor: Salvatore Cannella

Copyright (C) 2016 Rocio Ramos-Hernández et al. This is an open access article distributed under the Creative Commons Attribution License, which permits unrestricted use, distribution, and reproduction in any medium, provided the original work is properly cited.

\begin{abstract}
One of the byproducts generated in the cane sugar production is molasses, which is used for ethanol distillation. However, one of the problems of distilleries is vinasse. Vinasse is highly water pollutant and is dumped untreated in lakes or rivers and damages the environment. The company FALA developed a pilot plant that uses vinasse to produce a type of livestock feed called MD60. In this paper, the impact of the pilot plant's scale-up in the key processes of the company's supply chain is analyzed. With the help of a sensitivity analysis, this study finds the values that would allow the company to improve its order fulfillment indicator and to increase profits, assuming an expected demand by the introduction of this new product into the market. The results show that (1) the pilot plant fulfills $32 \%$ of the orders, (2) according to the current vinasse storage capacity, it is possible to fulfill up to $77 \%$ of the orders by scaling up the pilot plant, (3) to satisfy $100 \%$ of the orders, it is necessary to use all the vinasse generated, and (4) the highest profit is reached by processing all the vinasse and by considering the upper sale price.
\end{abstract}

\section{Introduction}

The sugar industry is one of the most important in the world due to the products and byproducts generated from its production. These become raw material for many supply chains, including ethanol, biofuels, beverages, and pharmaceutical products. According to OECD/FAO [1], trends in sugar production indicate that, by $2023,86 \%$ of the sugar globally produced will be obtained from sugar cane, and only a small portion will be extracted from sugar beet.

One of the products generated by the sugar industry is molasses, also called black treacle. The thick fluid is similar to honey but darker. According to experts, the darker it is, the more flavor and nutrients it has. For the international market, cane molasses have four main uses: (1) livestock feed, due to their concentration of calcium, chloride, and magnesium; (2) ethanol production; (3) reprocessing for sugar production; and (4) production of yeast, citric acid, and lysine, among others [2].

When molasses are used for ethanol production, the new byproduct or wastewater called vinasse is generated. Vinasse is a liquid residue remaining from the fermentation and distillation of alcoholic liquors. It has a dark, red color, ranging from crimson to almost black. Similarly, it has a strong odor, moderately acidic $\mathrm{pH}$, temperature close to $85^{\circ} \mathrm{C}$, and a biochemical oxygen demand (BOD) between 70 and $80 \mathrm{~g} / \mathrm{L}$. Vinasse is also composed of $93 \%$ water, $2 \%$ inorganic compounds (potassium, calcium, sulfates, chlorides, nitrogen, phosphorus, etc.), and $5 \%$ organic compounds that volatilize when heated at $650^{\circ} \mathrm{C}$ [3].

Vinasse from the ethanol industry is one of the major environmental pollutants. According to Moraes et al. [4], for every liter of produced ethanol, between 10 and 18 liters of vinasse are also generated, depending on the distilling 
process. Moreover, vinasse is usually discharged untreated into bodies of water, and it consequently pollutes surface water and groundwater [5]. Furthermore, the growing ethanol production from cane juices and molasses to use it as automotive fuel [6] greatly increases the risk of further pollution if technologies that help reduce pollutants are not implemented.

According to CONADESUCA [7], Mexico produces 190 million liters of ethanol each year, and, considering the aforementioned ethanol-vinasse relationship, this equals 1,900 million liters of vinasse, also per year. Undoubtedly, this is a major issue, not only due to the progressive deterioration of the environment, but also because this is economically ineffective since costs for collection, transport, and disposal of vinasse are constantly increasing [8]. However, if it is properly treated, vinasse can reduce its environmental impact, not to mention that it can become a continuous source of energy and raw materials with high added value [9].

For all these reasons, the company FALA (this name was given for confidentiality reasons) has designed a pilot plant for vinasse treatment, which, as a result, produces MD60, a type of livestock feed. Unfortunately, the plant does not have enough capacity to process $100 \%$ of the generated vinasse. Therefore, this paper analyzes the impact of the company's pilot plant scale-up in the key processes of its supply chain. Systems Dynamics (SD) is used to carry out this analysis.

The remainder of this paper is organized as follows: Section 2 briefly discusses previous works reporting vinasse use and treatment, and it explains the concept of industrial scale-up and study cases. Then, Section 3 describes the methodology employed to analyze pilot plant scale-up in FALA, while Section 4 presents and discusses the obtained results. Finally, Section 5 includes conclusions and recommendations for future work.

\section{Literature Review}

2.1. Vinasse Treatment to Reduce Its Environmental Impact. As previously mentioned, the chemicals contained in vinasse make it highly hazardous for the environment. However, if properly treated, it can be used as an energy source, livestock feed, or fertilizer [8] or for many other purposes. For instance, vinasse has been widely used to generate biogas from anaerobic digestion $[4,9,10]$. Similarly, it has been employed as a fertilizer for sugar cane fields, although the main problem with this is that a portion of vinasse may infiltrate into the soil and damage aquifers [11-16]. In addition, Colin et al. [17] and Sankaran et al. [18] used bacteria to retrieve effluents generated from the ethanol industry, while Akram et al. [10] assessed the potential of vinasse for biofuels production. Another use of the vinasses is the production of livestock feed $[5,19-22]$.

2.2. Industrial Scale-Up. Industrial scale-up aims at implementing, at a full scale, innovations or new technologies already tested in laboratories or pilot plants in order to improve the performance of industrial processes [23].
The literature has reported several innovations in industrial processes, such as biogas generation from industrial waste and residues [24-26], and the utilization of vinasse generated from distilling processes [27]. Similarly, other works have assessed the effectiveness of new technologies in improving the characteristics of heavy crude oil [28], reducing the environmental impact caused by the textile dyeing process [29], treating wastewater from a polyvinyl chloride production plant [30], and obtaining value-added products through biorefineries whose raw materials include biomass [31] and waste and residues [32, 33]. However, despite their success, most of these innovations have been tested only in laboratories or pilot plants. However, in some cases, their economic feasibility is analyzed and suggestions are provided for their implementation on a large scale.

Only few studies have implemented their proposed innovations and new technologies in the industry. Some of these implementations include a brand-new range of products from a steel company [34], performance improvement of activated sludge reactors [35], and the use of special equipment to control odors in a wastewater treatment plant [36]. In addition to reporting results from both a pilot plant and a full-scale industrial plant, these studies have highlighted the problems that arise from implementing the technologies at the large scale. Some of these problems include installation issues, failures in operational stability, and excessive economic costs, among others. Unfortunately, none of the works found reports scale-up in pilot plants that use vinasse for the production of livestock feed.

2.3. Use of Systems Dynamics for Industrial Scale-Up. To facilitate industrial scale-up, certain tools must be employed to assess the impact on production processes, as well as the problems, costs, and benefits that would be brought by the implementation of innovations and new technologies into the plant. Simulation, especially System Dynamics (SD), is a tool that enables assessing these variables. SD is based on a holistic system analysis, which is why simulation models designed through it demonstrate the behavior that would emerge in the system if any of its components are modified [37-39]. This is the main reason why SD has been widely employed to analyze and test different alternatives that modify the performance of many industrial sectors, including the cement industry [4042], the steel industry [43,44], the oil industry [45], and the automotive industry, and supply chains $[46,47]$.

None of the articles found to support this work report the use of SD to simulate the large-scale implementation of innovations and technologies previously tested in a laboratory or in pilot plants. However, one particular study developed a simulation model that analyzed increased vinasse generation as the result of a surge in bioethanol production [48].

2.4. Complex Supply Chains. The structure of supply chains is complex due to the quantity of suppliers and customers involved $[49,50]$. For this reason, different tools and techniques have been developed for their analysis, evaluation, and decision-making; one of these techniques is simulation. Considering its strengths, compared with mathematical programming methods or stochastic models, simulation 
especially through SD enables the user to find, analyze, and learn about the dynamic behaviors of the system studied, which is helpful in the decision-making process [51].

$\mathrm{SD}$ has been used to analyze the complexity of different types of supply chains [52, 53]. For example, Kumar and Kumar [54] study the effects of the lack of suppliers in healthcare supply chains for rural communities, caused by their geographical location, Lee and Chung [55] assess the coordination among the links of perishable food supply chains, since it is critical to guarantee the freshness of theirs products. Sagardi et al. [6] evaluate the feasibility of the biofuel supply chain in Mexico analyzing the ethanol production and three key variables were identified to develop this sector: the availability of raw materials, the production capacity, and the reduction of carbon dioxide emissions. Peng et al. [56] simulate the behavior of a postseismic relief supply chain, produced by information delay and damaged road infrastructure. Cannella et al. [53] tested the effect of inventory record inaccuracy in an information supply chain, finding that it causes instability among the links of the supply chain.

However, the analysis of the state of the art indicates that none of the research works found (1) addresses the impact of industrial scale-up of vinasse treatment over a supply chain and (2) uses SD to assess industrial scale-up. These are two aspects fully analyzed in this work.

To analyze the complexity of FALA's supply chain, the use of a simulation tool as SD is necessary.

\section{Materials and Methods}

The company FALA was used to assess the impact of pilot plant scale-up in the key processes of an ethanol supply chain. This company is located in the South of Mexico, and it is a national pioneer in the use of vinasse to produce livestock feed in a pilot plant that was developed by its research department. Figure 1 shows the supply chain of the company.

The supply chain begins with the harvest of sugar cane, which is taken to the mills for sugar production. A residue that is generated in this process is molasses, and although they are commonly used as cattle feed, in this case they serve as raw material for FALA's production process. That is, the company uses molasses to produce ethanol, which is later used in various products, such as makeup, drugs, beverages, and biofuel.

In its distilling process, FALA generates around 11 liters of vinasse for every liter of ethanol. This type of residue is usually dumped untreated into water bodies, thus damaging the flora and fauna, because it diminishes the oxygen concentration of these water bodies.

FALA perceived this problem and the serious environmental implications. It therefore decided to set up a pilot plant for vinasse treatment, obtaining MD60 as a result, which is a type of livestock feed. However, this pilot plant has the capacity to process only $2 \%$ of the daily-generated vinasse. The remainder is stored in holding tanks, but the storage generates additional costs. This paper therefore presents a SD model that assesses different scenarios in order to analyze the impact of the scale-up of the vinasse pilot plant in the key processes of the company's supply chain. The best alternative will be chosen based on results of two key performance indicators (KPIs). The following section describes the use of $\mathrm{SD}$ to develop the evaluation model.

3.1. Causal Diagram. A causal diagram is a graphical tool that helps represent the behavior of a system and the different interactions among its variables. Causal diagrams consist of variables connected through arrows that indicate cause-effect relationships $(A \rightarrow B)$. These relationships can be either positive or negative. If a relationship is positive, an increase in the cause will produce an increase in the effect, or a decrease in the cause will produce a decrease in the effect. Nevertheless, if the relationship is negative, any increase in the cause will produce a decrease in the effect, or any decrease in the cause will produce an increase in the effect.

Figure 2 depicts the causal diagram used to study industrial scale-up in the vinasse pilot plant. Some of the variables identified include master production schedule, molasses tank, ethanol production, ethanol production capacity, MD60 production capacity, and finished product inventory.

The feedback loops of the causal diagram are described as follows:

(i) Loop B1: it has a positive impact on the amount of orders requested from the supplier. However, if the amount of order increases, the molasses inventory of the supplier decreases or vice versa.

(ii) Loop B2: if the molasses inventory increases, the ethanol production may also increase, and when the ethanol production increases, the molasses inventory will decrease. Similarly, the ethanol production depends on the production capacity of the plant.

(iii) Loop B3: when vinasse inventory increases, MD60 production also rises. An increase in MD60 production causes a decrease in vinasse inventory, which limits MD60 production.

(iv) Loop B4: if the variable MD60 production increases, the finished product inventory will also increase. If there are high levels of finished product inventory, MD60 production decreases.

3.2. Equations. This section describes the equations from the simulation model that correspond to the key processes of the supply chain:

Orders from Supplier. FALA receives daily orders from the supplier (DOS) depending on the condition shown by (1). Thus, during harvest season, the company daily receives between 25 and 30 shipments with 30 tons of molasses. However, when it is not harvest season, the company receives maximum 8 shipments, although sometimes there is no daily supply:

$$
\text { DOS }= \begin{cases}\text { With harvest, } & 25 \leq \text { DOS } \leq 30, \\ \text { Without harvest, } & 0 \leq \text { DOS } \leq 8 .\end{cases}
$$




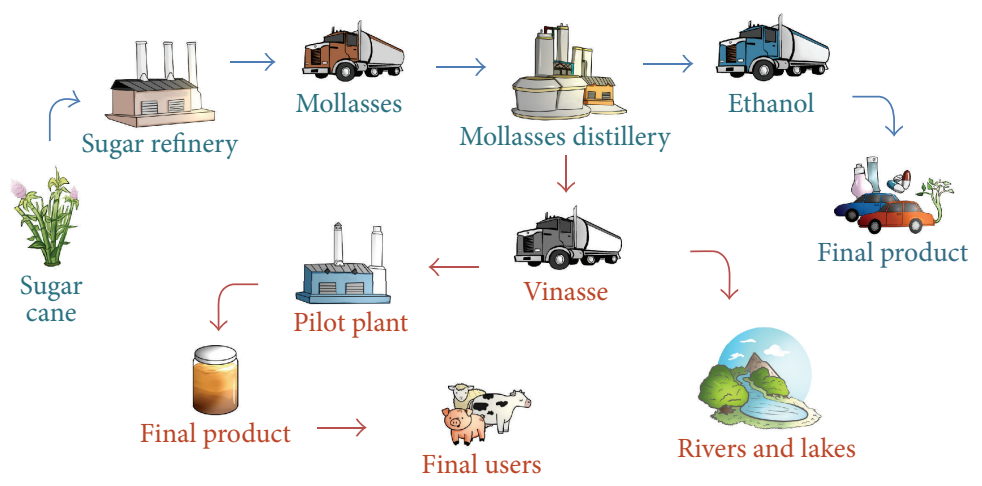

FIGURE 1: Supply chain of FALA.

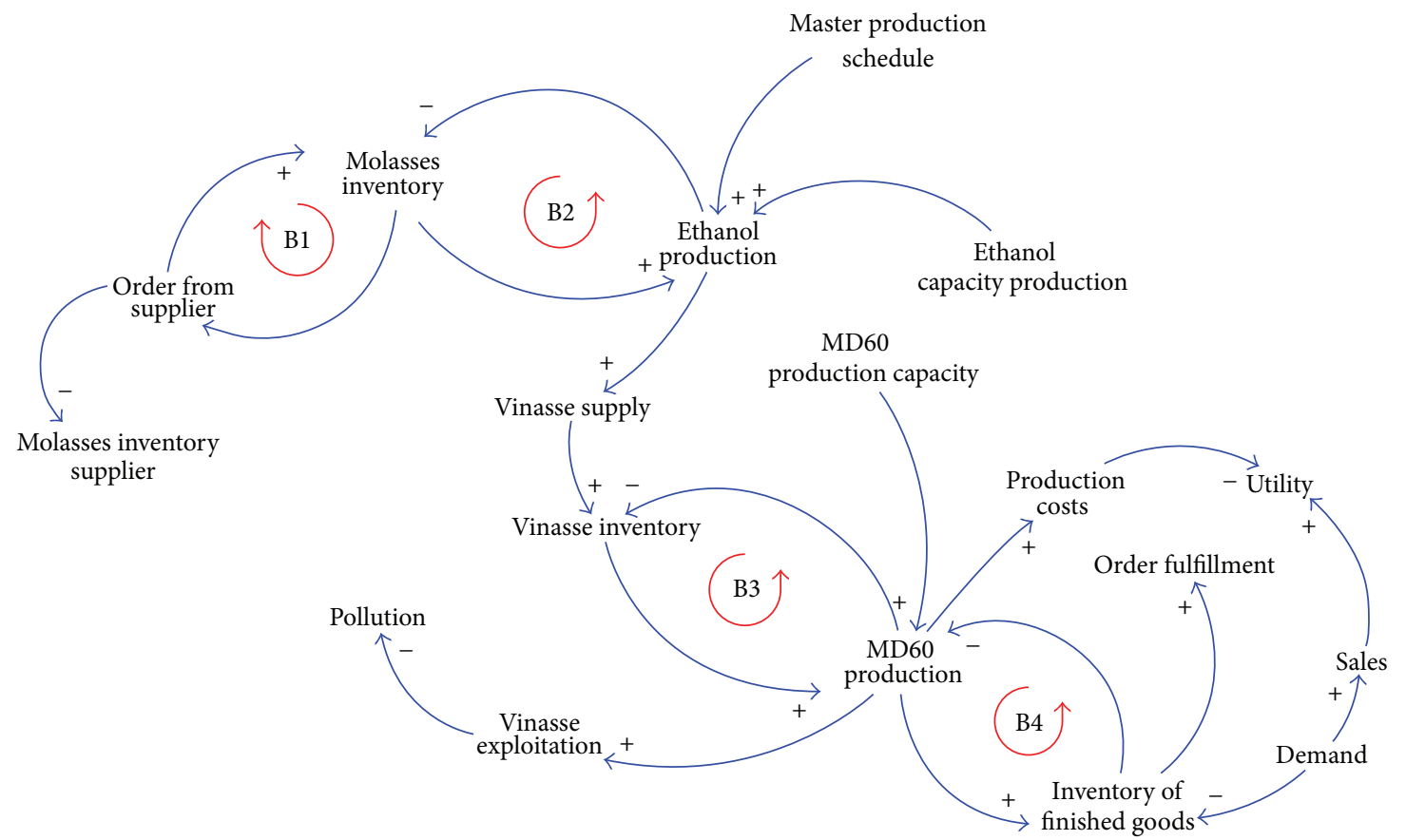

FIgURE 2: Causal loop diagram of the scale-up of plant pilot of vinasse.

FALA uses the distillation method for ethanol production (EP). Therefore, the amount of ethanol obtained per ton of molasses can vary. To represent this variability, the RANDOM function is used, which generates a random value from a range of preestablished values. In this case, and according to historical data, the minimum and maximum values were 235,118 and 292,397 liters of ethanol:

$$
\mathrm{EP}=\operatorname{RANDOM}(235.118,292.397) .
$$

Vinasse $(V)$ is the raw material of FALA's pilot plant, and it depends on EP. Every liter of produced ethanol generates around 11 liters of vinasse (os). This relationship is expressed by

$$
V=\mathrm{EP} * \mathrm{os}
$$

Due to the great amount of vinasse that is generated, FALA reuses it as its raw material. Its supply policy depends on the demand of the livestock feed, MD60. That is, if there is a high demand of MD60, vinasse is treated; otherwise, it is sent to holding tanks as expressed by

$$
\mathrm{VHT}=\mathrm{DOV}-\mathrm{VP} .
$$

In this equation, VHT stands for the vinasse that is sent to the holding tanks. It is the difference between the daily-obtained vinasse (DOV) and the vinasse that is temporarily stored in a pit (VP) for its further treatment. The amount of vinasse in $\mathrm{VP}_{t+1}$ is determined by the condition expressed by

$$
\mathrm{VP}_{t+1}= \begin{cases}\text { If } \mathrm{DOV} \leq \mathrm{CVP}-\mathrm{FP}_{t}, & \text { Then } \mathrm{DOV}, \\ \text { else, } & \mathrm{CVP}-\mathrm{FP}_{t} .\end{cases}
$$


If the amount of daily-obtained vinasse (DOV) is smaller than the difference between the capacity of the pit (CVP) and the amount stored in $\mathrm{VP}_{t}$ (in time $t$ ), DOV is then stored in $\mathrm{VP}_{t+1}$; otherwise, the amount stored is only what results from this difference.

The pilot plant has a batch production system (BPS) for MD60 production. This system works as expressed in

$$
\mathrm{BPS}=2 \mathrm{PR}\left(L_{1}+4 L_{2}\right) .
$$

In this equation, $\mathrm{PR}$ is the percentage of vinasse retrieved and $L_{1}$ is the initial load added, while $L_{2}$ stands for four additional loads with different values which are added throughout the MD60 production process.

As regards industrial scale-up, MD60 production in the full-scale industrial plant (IP) follows the behavior described in

$$
\mathrm{IP}=\sum_{i=1}^{n} \mathrm{PR}\left(\mathrm{CF}_{h}\right)
$$

where $\mathrm{CF}_{h}$ is the continuous flow per hour and $n$ represents the number of work hours in a day.

Both plants have PR that behaves as a normal distribution (see (8)) with a mean of $11.58 \%$ and a standard deviation of $1.8 \%$ :

$$
\mathrm{PR}=N(11.58,1.8)
$$

The Company's Inventories. Inventory of MD60 (IMD), inventory of vinasse (IV), and inventory of molasses (IM) behave as expressed in (8), (9), and (10), respectively:

$$
\begin{aligned}
\mathrm{IMD} & =\left.\mathrm{IMD}\right|_{t=0}+\int_{0}^{t}(V * \mathrm{PR}-s), \\
\mathrm{IV} & =\left.\mathrm{IV}\right|_{t=0}+\int_{0}^{t}\left(m * r_{\text {molasses }} * \mathrm{os}-V\right), \\
\mathrm{IM} & =\left.\mathrm{IM}\right|_{t=0}+\int_{0}^{t}\left(a * Q_{\text {molasses }}-m\right) .
\end{aligned}
$$

In these equations, $s$ represents the effective sales of MD60, $m$ is the amount of molasses to be processed, $r_{\text {molasses }}$ is the yield of molasses per ton of ethanol, $a$ is the amount of orders requested from the molasses supplier, and $Q_{\text {molasses }}$ is the amount of molasses that is ordered. The company's molasses inventory is considered in the model, since MD60 depends on ethanol production, which in turn could not be achieved with a molasses inventory that is low or inexistent.

Two performance indicators were considered to assess the impact of the pilot plant scale-up in the supply chain of the company FALA: order fulfillment of daily demand (OFDD) and profits $(P)$ gained in 365 days. On one hand, OFDD is calculated by

$$
\mathrm{OFDD}=\frac{1}{j} \sum_{i=1}^{j} \frac{S_{i}}{D_{i}} * 100 \%,
$$

TABLE 1: Initial parameters of simulation.

\begin{tabular}{lcc}
\hline Plant & Pilot & Scale-up \\
\hline Capacity vinasse pit (L) & $1,500,000$ & $1,500,000$ \\
Vinasse production for day (L/d) & 19,200 & $1,320,000$ \\
Percentage of vinasse retrieve (L) & 11.58 & 11.58 \\
Capacity storage MD60 (kg) & 15,000 & 950,000 \\
Order fulfillment (\%) & $32 \%$ & - \\
Profit (USD) & 34,600 & - \\
\hline
\end{tabular}

where $j$ stands for the amount of days when there is product demand, $D$ represents the amount of this demand, and $S$ stands for the amount of effective sales.

On the other hand, profits (see (13)) are the difference between total earnings (TE) and total costs (TC):

$$
P=\text { TE }- \text { TC. }
$$

The next step in the methodology of SD is to develop the Forrester diagram considering the above equations.

\section{Results and Discussion}

The model simulation is run with software Stella ${ }^{\circledR}$ V10.0.4 during 52 weeks. DT $=1$, and hours is the time unit employed. Demand of MD60 is represented by a normal distribution with a mean of $164,000 \mathrm{~kg}$ and a standard deviation of $10,000 \mathrm{~kg}$. The warehouse used to store the finished product has a storage capacity for $950,000 \mathrm{~kg}$ of MD60. It is assumed that the industrial plant would work 24 hours every day from Monday to Sunday. However, in these 52 weeks, there are two weeks of production stoppage due to the maintenance of the ethanol distillery plant.

Table 1 shows the parameters from both the pilot plant and the full-scale industrial plant. The parameters capacity vinasse pit, vinasse production for day, and capacity storage were chosen according to the technical specifications of the pilot and scale-up plant. Percentage of vinasse retrieve, order fulfillment, and profit were obtained by historical data. As can be observed, OFDD in the pilot plant reaches only $32 \%$ and $P$ equals 34,600 USD. An increase in both indicators is expected with the implementation of a full-scale industrial plant.

Due to the low percentage of OFDD obtained, a sensitivity analysis was performed to find the values that satisfy $100 \%$ of the orders.

4.1. Sensitivity Analysis. A low percentage in OFDD in the pilot plant reflects the company's inability to satisfy a high demand of MD60. Therefore, to increase the values of the two performance indicators, a sensitivity analysis is carried out by modifying the values of the following variables: capacity vinasse pit (CVP), which represents the full capacity of the pit; continuous flow per hour $\left(\mathrm{CF}_{h}\right)$, which is obtained by a previous sensitivity analysis and represents the range where the flow can be continuous without stopping the production; initial raw material inventory (IIRM) and maintenance time (MT), which are defined through the experience of the company's managers; and finally sale price (SP) per kilogram, 
TABLE 2: Simulation output to achieve the maximum OFDD (\%).

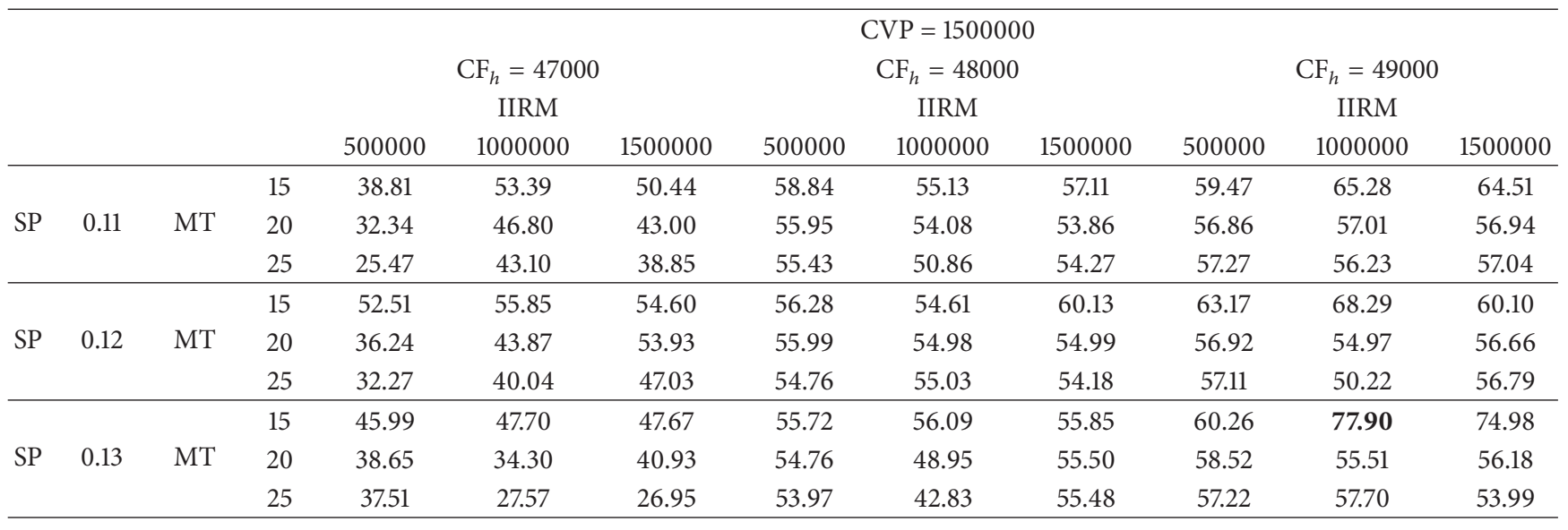

TABLE 3: Simulation output to achieve the higher profits (million USD).

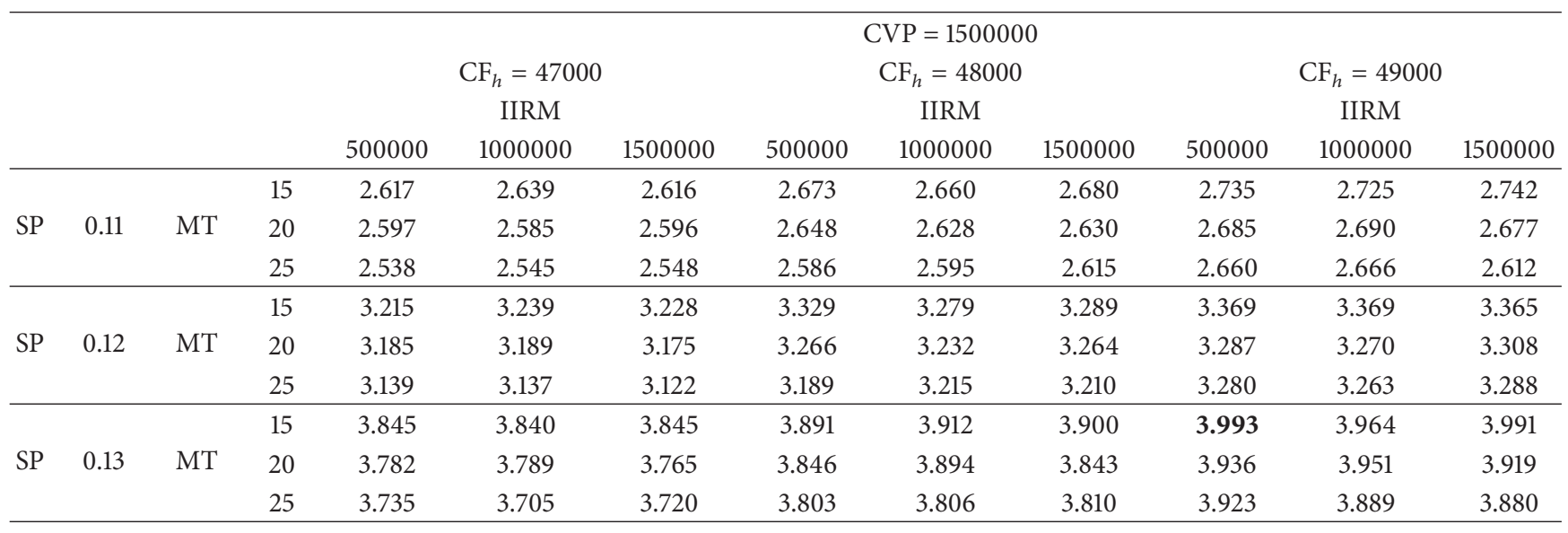

which is the range of the molasses' cost fluctuation, the biggest competitor of vinasses; all this is in order to improve performance indicators. Tables 2 and 3 present the results obtained of OFDD and P. 91 different scenarios were tested, considering the following values:

$$
\begin{aligned}
& \text { CVP (L): 1,500,000. } \\
& \mathrm{CF}_{h}(\mathrm{~L}): 47,000,48,000 \text {, and } 49,000 . \\
& \operatorname{IIRM}(\mathrm{L}): 500,000,1,000,000 \text {, and } 1,500,000 . \\
& \text { MT (days): } 15,20 \text {, and } 25 \text {. } \\
& \text { SP (USD): } 0.11,0.12 \text {, and } 0.13 \text {. }
\end{aligned}
$$

In Table 2, there is a summary of the development of 91 scenarios to achieve $100 \%$ of OFDD, but the maximum value of OFDD achieved is $77.90 \%$, obtained with the next combination CVP $=1,500,000 \mathrm{~L}, \mathrm{CF}_{h}=49,000 \mathrm{~L}, \operatorname{IIRM}=1,000,000 \mathrm{~L}$, $\mathrm{MT}=15$ days, and SP $=0.13$ USD. In the case of profit, Table 3 shows the result obtained and the major profits achieved are 3,993,269.00 USD with $\mathrm{CVP}=1,500,000 \mathrm{~L}, \mathrm{CF}_{h}=$ $49,000 \mathrm{~L}, \operatorname{IIRM}=1,000,000 \mathrm{~L}, \mathrm{MT}=15$ days, and $\mathrm{SP}=$ 0.13 USD.

Results of the first sensitivity analysis still show inability to fully satisfy the product demand. Thus, a second analysis is carried out, this time by considering that vinasse cannot be completely processed due to capacity constraints, which is why it is sent to holding tanks (Table 4). In this second case, the following values are analyzed:

$$
\begin{aligned}
& \operatorname{CVP}(\mathrm{L}): 1,500,000 . \\
& \mathrm{CF}_{h}(\mathrm{~L}): 47,000,48,000,49,000 . \\
& \operatorname{IIRM}(\mathrm{L}): 500,000,1,000,000 \text {, and } 1,500,000 . \\
& \mathrm{MT} \text { (days): 15, 20, and } 25 . \\
& \text { SP(USD): 0.11, 0.12, and 0.13. } \\
& \text { Holding tank (L) }=15,000,000 .
\end{aligned}
$$

As shown in Table 4, three different scenarios allow obtaining $100 \%$ of OFDD; the combinations to achieve are shown in Table 5. However, different scenarios are close to $100 \%$, as $99.99 \%, 99.90 \%$, and others. This is because of uncertainty and variability in the following variables and processes: demand, production process of ethanol, percentage of recuperation of vinasse, and inventory of raw material.

Table 6 shows the scenario to obtain the higher profits $(4,65,820$ USD). This scenario has the following combination: CVP: 1,500,000 (L); $\mathrm{CF}_{h}$ : 49,000 (L); IIRM: 1,000,000 (L); MT: 15 (days); SP: 0.13 (USD); and holding tank =15,000,000 (L). 
TABLE 4: Simulation output to achieve 100\% OFDD (\%).

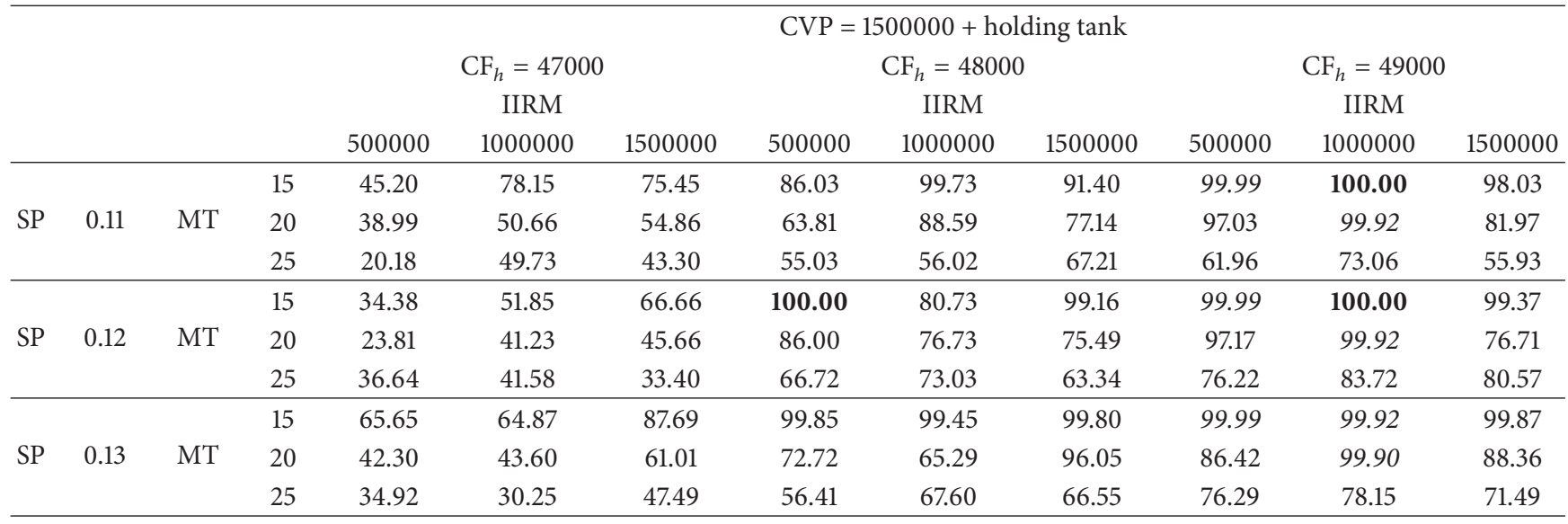

TABLE 5: Scenarios to achieve 100\% OFDD.

\begin{tabular}{lccc}
\hline Parameters & & OFDD $=100 \%$ & Scenario 3 \\
\hline CVP (L) & Scenario 1 & Scenario 2 & $1500000+$ holding tank \\
CF $_{h}$ (L) & $1500000+$ holding tank & $1500000+$ holding tank & 49000 \\
IIRM (L) & 48000 & 49000 & 1000000 \\
MT (days) & 500000 & 1000000 & 15 \\
SP (USD) & 15 & 15 & 0.12 \\
\hline
\end{tabular}

TABLE 6: Simulation output to achieve the higher profits (million USD).

\begin{tabular}{|c|c|c|c|c|c|c|c|c|c|c|c|c|}
\hline & & & & \multicolumn{9}{|c|}{$\mathrm{CVP}=1500000+$ holding tank } \\
\hline & & & & \multirow{2}{*}{\multicolumn{3}{|c|}{$\begin{array}{c}\mathrm{CF}_{h}=47000 \\
\text { IIRM }\end{array}$}} & \multirow{2}{*}{\multicolumn{3}{|c|}{$\begin{array}{c}\mathrm{CF}_{h}=48000 \\
\text { IIRM }\end{array}$}} & \multirow{2}{*}{\multicolumn{3}{|c|}{$\begin{array}{c}\mathrm{CF}_{h}=49000 \\
\text { IIRM }\end{array}$}} \\
\hline & & & & & & & & & & & & \\
\hline & & & & 500000 & 1000000 & 1500000 & 500000 & 1000000 & 1500000 & 500000 & 1000000 & 1500000 \\
\hline \multirow{3}{*}{ SP } & \multirow{3}{*}{0.11} & \multirow{3}{*}{ MT } & 15 & 2.719 & 2.741 & 2.748 & 2.784 & 2.633 & 2.755 & 2.741 & 2.696 & 2.700 \\
\hline & & & 20 & 2.727 & 2.718 & 2.740 & 2.741 & 2.764 & 2.770 & 2.730 & 2.679 & 2.783 \\
\hline & & & 25 & 2.699 & 2.711 & 2.705 & 2.720 & 2.715 & 2.746 & 2.729 & 2.675 & 2.747 \\
\hline \multirow{3}{*}{ SP } & \multirow{3}{*}{0.12} & \multirow{3}{*}{ MT } & 15 & 3.356 & 3.349 & 3.362 & 3.252 & 3.417 & 3.385 & 2.856 & 3.344 & 3.360 \\
\hline & & & 20 & 3.344 & 3.341 & 3.360 & 3.409 & 2.767 & 3.386 & 2.838 & 3.332 & 3.412 \\
\hline & & & 25 & 3.330 & 3.322 & 3.321 & 3.366 & 2.733 & 3.355 & 2.836 & 3.315 & 3.365 \\
\hline \multirow{3}{*}{ SP } & \multirow{3}{*}{0.13} & \multirow{3}{*}{ MT } & 15 & 3.988 & 3.981 & 3.987 & 3.974 & 3.984 & 4.032 & 4.024 & 4.066 & 3.885 \\
\hline & & & 20 & 4.000 & 3.998 & 3.996 & 4.030 & 4.012 & 4.013 & 4.015 & 4.034 & 4.046 \\
\hline & & & 25 & 3.946 & 3.945 & 3.942 & 3.986 & 4.006 & 3.848 & 4.014 & 3.942 & 4.020 \\
\hline
\end{tabular}

Although this scenario delivers the highest profit, it only achieves $99.92 \%$ of OFDD as shown in Table 4 . This is due to the variability in the key process of the supply chain, which does not allow satisfying $100 \%$ of OFDD.

By using both the vinasse pit and the holding tank, the company could reach $100 \%$ of OFFD and obtain the highest profits. However, the use of the holding tank as storage will generate an extra cost that, given the improvement achieved for both OFFDD and P, is worth the investment.

Also, the sensitivity analysis shows a behavioral pattern among the set values, without missing the systems uncertainty and variability. In general, a larger MT decreases the OFDD and $P$. On the other hand, a larger inventory and a larger $\mathrm{CF}_{h}$ increase the OFDD and $P$. These relations prove the logic described in the causal diagram.

\section{Conclusions and Future Work}

This paper evaluates the impact of pilot plant scale-up in the key processes of a supply chain. The pilot plant reuses vinasse generated in ethanol production to produce livestock feed. The major contribution of this research is the identification of those key processes from the company's supply chain that could be affected in the pilot plant scale-up process. A sensitivity analysis helps to find three scenarios to achieve $100 \%$ OFDD. One scenario allowed achieving the higher 
profits. The key processes of the supply chain of FALA are procurement of vinasses and production of ethanol because the major variability and uncertainty are present here. As future work, it is necessary to assess, by means of sustainability indicators, the environmental benefits of the full-scale industrial plant. Likewise, the relationship costbenefit must be evaluated by considering time dedicated and investments made to set up the full-scale plant. Finally, although this research considered only two performance indicators, a multicriteria analysis is recommended in order to improve decision-making.

\section{Competing Interests}

The authors declare that there is no conflict of interests regarding the publication of this paper.

\section{Acknowledgments}

The authors are grateful to National Technological of Mexico for supporting this research. This study was sponsored by the National Council of Science and Technology (CONACYT), as well as by the Public Education Secretary (SEP) through PRODEP.

\section{References}

[1] OECD/FAO, OCDE-FAO Perspectivas Agrícolas 2014, OECD, 2014.

[2] M. Manfredini and C. Cavani, "Distillery effluents as animal feed: the use of condensed beet molasses stillage (CBMS) in broiler feeding," Animal Feed Science and Technology, vol. 5, no. 3, pp. 233-239, 1980.

[3] J. F. Urbano, J. Evagenlista, A. C. De Castro, J. Escher, and C. Fontanetti, "Sugar cane vinasse in water bodies: impact assessed by liver histopathology in tilapia," Ecotoxicology and Environmental Safety, vol. 110, pp. 239-245, 2014.

[4] B. S. Moraes, M. Zaiat, and A. Bonomi, "Anaerobic digestion of vinasse from sugarcane ethanol production in Brazil: challenges and perspectives," Renewable and Sustainable Energy Reviews, vol. 44, pp. 888-903, 2015.

[5] C. A. Christofoletti, J. P. Escher, J. E. Correia, J. F. U. Marinho, and C. S. Fontanetti, "Sugarcane vinasse: environmental implications of its use," Waste Management, vol. 33, no. 12, pp. 27522761, 2013.

[6] M. A. Sagardi, C. Sánchez, G. Cortes, G. Alor, and M. G. Cedillo, "Dynamic analysis of feasibility in ethanol supply chain for biofuel production in Mexico," Applied Energy, vol. 123, pp. 358367, 2014.

[7] CONADESUCA, Cifras Definitivas Zafra 2014-2015, 2016, http://www.conadesuca.gob.mx/documentos\%20de\%20interes/ CIFRAS\%20DEFINITIVAS\%20ZAFRA\%202014-15.pdf.

[8] SAGARPA, "Estudio de factibilidad para la instalación de una destileria de etanol en Atencingo," http://www.sagarpa.gob.mx/ Delegaciones/puebla/Documents/Evaluaciones\%20Externas/ 2011/Estudio\%20Fact\%20Int\%20Destileria\%20Etanol\%20Atencingo.pdf.

[9] C. E. C. Nogueira, S. N. M. De Souza, V. C. Micuanski, and R. L. Azevedo, "Exploring possibilities of energy insertion from vinasse biogas in the energy matrix of Paraná State, Brazil,"
Renewable and Sustainable Energy Reviews, vol. 48, pp. 300-305, 2015.

[10] M. Akram, C. K. Tan, R. Garwood, and S. M. Thai, "Vinassea potential biofuel-cofiring with coal in a fluidised bed combustor," Fuel, vol. 158, pp. 1006-1015, 2015.

[11] G. Ortegón, F. Muñoz Arboleda, L. Candela, K. Tamoh, and J. Valdes-Abellan, "Vinasse application to sugar cane fields. Effect on the unsaturated zone and groundwater at Valle del Cauca," Science of the Total Environment, vol. 539, pp. 410-419, 2016.

[12] M. Andalib, E. Elbeshbishy, N. Mustafa, H. Hafez, G. Nakhla, and J. Zhu, "Performance of an anaerobic fluidized bed bioreactor (AnFBR) for digestion of primary municipal wastewater treatment biosolids and bioethanol thin stillage," Renewable Energy, vol. 71, pp. 276-285, 2014.

[13] M. Coca, V. M. Barrocal, S. Lucas, G. González-Benito, and M. T. García-Cubero, "Protein production in Spirulina platensis biomass using beet vinasse-supplemented culture media," Food and Bioproducts Processing, vol. 94, pp. 306-312, 2015.

[14] C. Wang, X.-Q. Zhao, T. Aizawa, M. Sunairi, and R.-F. Shen, "High aluminum tolerance of Rhodotorula sp. RS1 is associated with thickening of the cell wall rather than chelation of aluminum ions," Pedosphere, vol. 23, no. 1, pp. 29-38, 2013.

[15] E. J. Olguín, G. Sánchez-Galván, R. E. González-Portela, and M. López-Vela, "Constructed wetland mesocosms for the treatment of diluted sugarcane molasses stillage from ethanol production using Pontederia sagittata," Water Research, vol. 42, no. 14, pp. 3659-3666, 2008.

[16] V. Parnaudeau, N. Condom, R. Oliver, P. Cazevieille, and S. Recous, "Vinasse organic matter quality and mineralization potential, as influenced by raw material, fermentation and concentration processes," Bioresource Technology, vol. 99, no. 6, pp. 1553-1562, 2008.

[17] V. L. Colin, A. Juárez Cortes, J. D. Aparicio, and M. J. Amoroso, "Potential application of a bioemulsifier-producing actinobacterium for treatment of vinasse," Chemosphere, vol. 144, pp. 842847, 2016.

[18] K. Sankaran, M. Premalatha, M. Vijayasekaran, and V. T. Somasundaram, "DEPHY project: distillery wastewater treatment through anaerobic digestion and phycoremediation-a green industrial approach," Renewable and Sustainable Energy Reviews, vol. 37, pp. 634-643, 2014.

[19] P.-J. Zhang, Z. Zhao, S. Yu, Y. Guan, D. Li, and X. He, "Using strong acid-cation exchange resin to reduce potassium level in molasses vinasses," Desalination, vol. 286, pp. 210-216, 2012.

[20] J. A. Mathews, H. Tan, M. J. B. Moore, and G. Bell, "A conceptual lignocellulosic 'feed+fuel' biorefinery and its application to the linked biofuel and cattle raising industries in Brazil," Energy Policy, vol. 39, no. 9, pp. 4932-4938, 2011.

[21] S. Nitayavardhana and S. K. Khanal, "Innovative biorefinery concept for sugar-based ethanol industries: production of protein-rich fungal biomass on vinasse as an aquaculture feed ingredient," Bioresource Technology, vol. 101, no. 23, pp. 90789085, 2010.

[22] C. T. Sanada, S. G. Karp, M. R. Spier et al., "Utilization of soybean vinasse for $\alpha$-galactosidase production," Food Research International, vol. 42, no. 4, pp. 476-483, 2009.

[23] G. Donati and R. Paludetto, "Scale up of chemical reactors," Catalysis Today, vol. 34, no. 3-4, pp. 483-533, 1997.

[24] R. Baciocchi, A. Corti, G. Costa, L. Lombardi, and D. Zingaretti, "Storage of carbon dioxide captured in a pilot-scale biogas upgrading plant by accelerated carbonation of industrial residues," Energy Procedia, vol. 4, pp. 4985-4992, 2011. 
[25] A. Meneses-Jácome, R. Diaz-Chavez, H. I. VelásquezArredondo, D. L. Cárdenas-Chávez, R. Parra, and A. A. RuizColorado, "Sustainable energy from agro-industrial wastewaters in Latin-America," Renewable and Sustainable Energy Reviews, vol. 56, pp. 1249-1262, 2016.

[26] E. Posadas, M. L. Serejo, S. Blanco, R. Pérez, P. A. GarcíaEncina, and R. Muñoz, "Minimization of biomethane oxygen concentration during biogas upgrading in algal-bacterial photobioreactors," Algal Research, vol. 12, pp. 221-229, 2015.

[27] A. Robertiello, L. Angelini, and E. D’Addario, "Upgrading of agricultural and agro-industrial wastes: the desalification of concentrated beet vinasses," Agricultural Wastes, vol. 4, no. 5, pp. 397-405, 1982.

[28] L. C. Castañeda, J. A. D. Muñoz, and J. Ancheyta, "Current situation of emerging technologies for upgrading of heavy oils," Catalysis Today, vol. 220-222, pp. 248-273, 2014.

[29] A. Angelis-Dimakis, A. Alexandratou, and A. Balzarini, "Value chain upgrading in a textile dyeing industry," Journal of Cleaner Production, 2016.

[30] D. Prieto, N. Swinnen, L. Blanco et al., "Drivers and economic aspects for the implementation of advanced wastewater treatment and water reuse in a PVC plant," Water Resources and Industry, vol. 14, pp. 26-30, 2016.

[31] B. Kamm, P. Schönicke, and C. Hille, "Green biorefineryindustrial implementation," Food Chemistry, vol. 197, pp. 13411345, 2016.

[32] C. Sawatdeenarunat, D. Nguyen, K. C. Surendra et al., "Anaerobic biorefinery: current status, challenges, and opportunities," Bioresource Technology, vol. 215, pp. 304-313, 2016.

[33] M. Zhang, L. Xie, Z. Yin, S. K. Khanal, and Q. Zhou, "Biorefinery approach for cassava-based industrial wastes: current status and opportunities," Bioresource Technology, vol. 215, pp. 50-62, 2016.

[34] F. Skarp and L.-E. Gadde, "Problem solving in the upgrading of product offerings-a case study from the steel industry," Industrial Marketing Management, vol. 37, no. 6, pp. 725-737, 2008.

[35] L. Zhang, S. Zhang, Y. Peng, X. Han, and Y. Gan, "Nitrogen removal performance and microbial distribution in pilot- and full-scale integrated fixed-biofilm activated sludge reactors based on nitritation-anammox process," Bioresource Technology, vol. 196, pp. 448-453, 2015.

[36] J. M. Estrada, N. J. R. Kraakman, R. Lebrero, and R. Muñoz, "Integral approaches to wastewater treatment plant upgrading for odor prevention: activated Sludge and Oxidized Ammonium Recycling," Bioresource Technology, vol. 196, pp. 685-693, 2015.

[37] M. G. Cedillo and C. Sánchez, Análisis Dinámico de Sistemas Industriales, Trillas, Barcelona, Spain, 1st edition, 2008.

[38] J. W. Forrester, "Industrial dynamics: a major breakthrough for decision makers," Harvard Business Review, vol. 36, pp. 37-66, 1958.

[39] J. D. Sterman, Business Dynamics: Systems Thinking and Modeling for a Complex World, Management, Irwin McGraw-Hill, 2000 .

[40] S. Anand, P. Vrat, and R. P. Dahiya, "Application of a system dynamics approach for assessment and mitigation of $\mathrm{CO}_{2}$ emissions from the cement industry," Journal of Environmental Management, vol. 79, no. 4, pp. 383-398, 2006.

[41] N. Ansari and A. Seifi, "A system dynamics model for analyzing energy consumption and $\mathrm{CO}_{2}$ emission in Iranian cement industry under various production and export scenarios," Energy Policy, vol. 58, pp. 75-89, 2013.
[42] J. Vargas and A. Halog, "Effective carbon emission reductions from using upgraded fly ash in the cement industry," Journal of Cleaner Production, vol. 103, pp. 948-959, 2015.

[43] N. Ansari and A. Seifi, "A system dynamics analysis of energy consumption and corrective policies in Iranian iron and steel industry," Energy, vol. 43, no. 1, pp. 334-343, 2012.

[44] W. Chen, X. Yin, and D. Ma, "A bottom-up analysis of China's iron and steel industrial energy consumption and $\mathrm{CO}_{2}$ emissions," Applied Energy, vol. 136, pp. 1174-1183, 2014.

[45] B. Kiani and M. Ali Pourfakhraei, "A system dynamic model for production and consumption policy in Iran oil and gas sector," Energy Policy, vol. 38, no. 12, pp. 7764-7774, 2010.

[46] A. Azadeh and H. Vafa Arani, "Biodiesel supply chain optimization via a hybrid system dynamics-mathematical programming approach," Renewable Energy, vol. 93, pp. 383-403, 2016.

[47] A. Barisa, F. Romagnoli, A. Blumberga, and D. Blumberga, "Future biodiesel policy designs and consumption patterns in Latvia: a system dynamics model," Journal of Cleaner Production, vol. 88, pp. 71-82, 2015.

[48] D. W. Ibarra-Vega, "Modeling waste management in a bioethanol supply chain: a system dynamics approach," DYNA, vol. 83, no. 195, pp. 99-104, 2016.

[49] L. Tang, K. Jing, J. He, and H. E. Stanley, "Complex interdependent supply chain networks: cascading failure and robustness," Physica A: Statistical Mechanics and Its Applications, vol. 443, pp. 58-69, 2016.

[50] R. Dominguez, S. Cannella, and J. M. Framinan, "On returns and network configuration in supply chain dynamics," Transportation Research Part E: Logistics and Transportation Review, vol. 73, pp. 152-167, 2014.

[51] S. Umeda and Y. T. Lee, "Design specifications of a generic supply chain simulator," in Proceedings of the Winter Simulation Conference, R. G. Ingalls, M. D. Rossetti, J. S. Smith, and B. A. Peters, Eds., pp. 1158-1166, December 2004.

[52] J. W. Forrester, "System dynamics-a personal view of the first fifty years," System Dynamics Review, vol. 23, no. 2-3, pp. 345358, 2007.

[53] S. Cannella, J. M. Framinan, M. Bruccoleri, A. P. BarbosaPóvoa, and S. Relvas, "The effect of inventory record inaccuracy in information exchange supply chains," European Journal of Operational Research, vol. 243, no. 1, pp. 120-129, 2015.

[54] D. Kumar and D. Kumar, "Modelling rural healthcare supply chain in India using system dynamics," Procedia Engineering, vol. 97, pp. 2204-2212, 2014.

[55] C.-F. Lee and C.-P. Chung, "An inventory model for deteriorating items in a supply chain with system dynamics analysis," Procedia-Social and Behavioral Sciences, vol. 40, pp. 41-51, 2012.

[56] M. Peng, Y. Peng, and H. Chen, "Post-seismic supply chain risk management: a system dynamics disruption analysis approach for inventory and logistics planning," Computers \& Operations Research, vol. 42, pp. 14-24, 2014. 


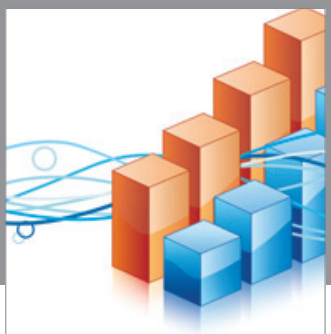

Advances in

Operations Research

vatem alat4

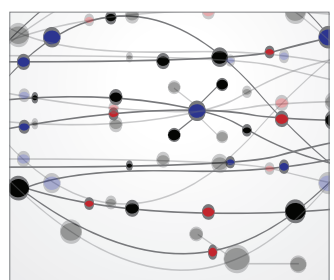

\section{The Scientific} World Journal
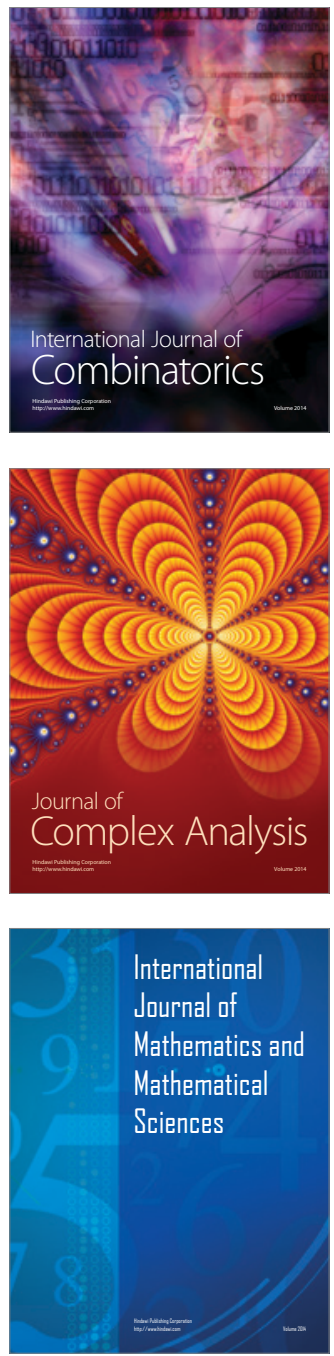
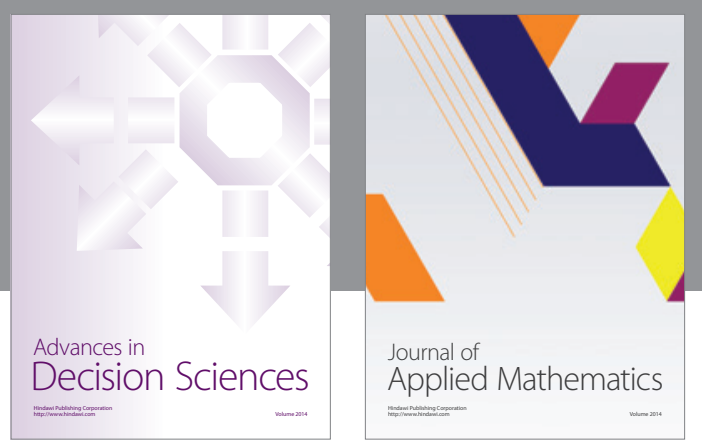

Algebra

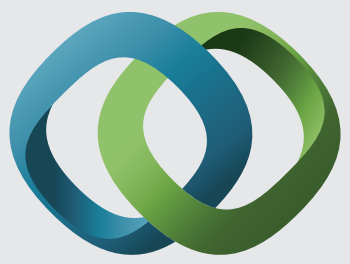

\section{Hindawi}

Submit your manuscripts at

http://www.hindawi.com
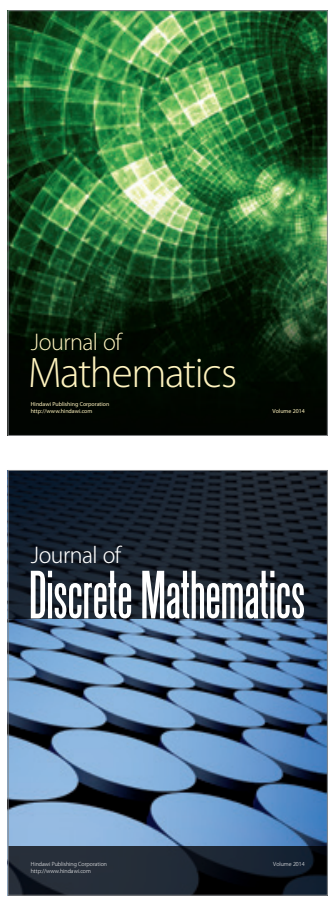

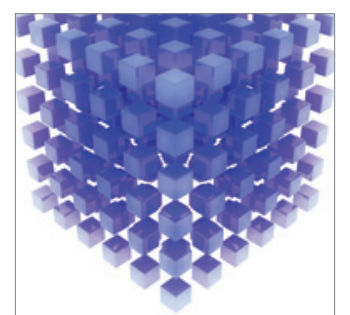

Mathematical Problems in Engineering
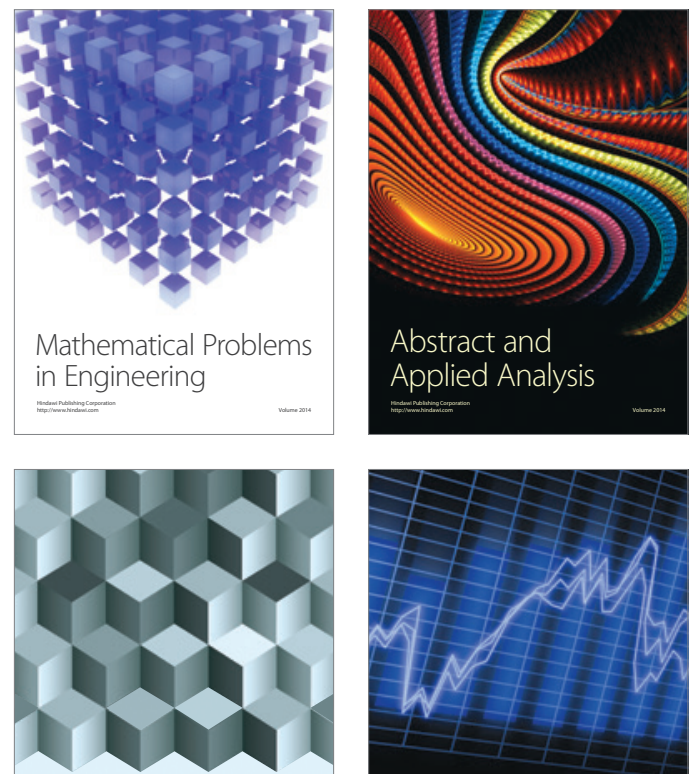

Journal of

Function Spaces

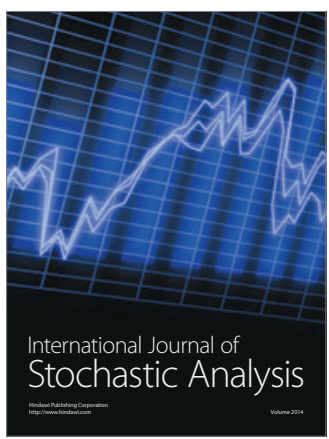

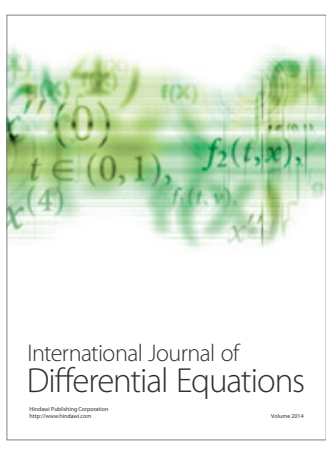
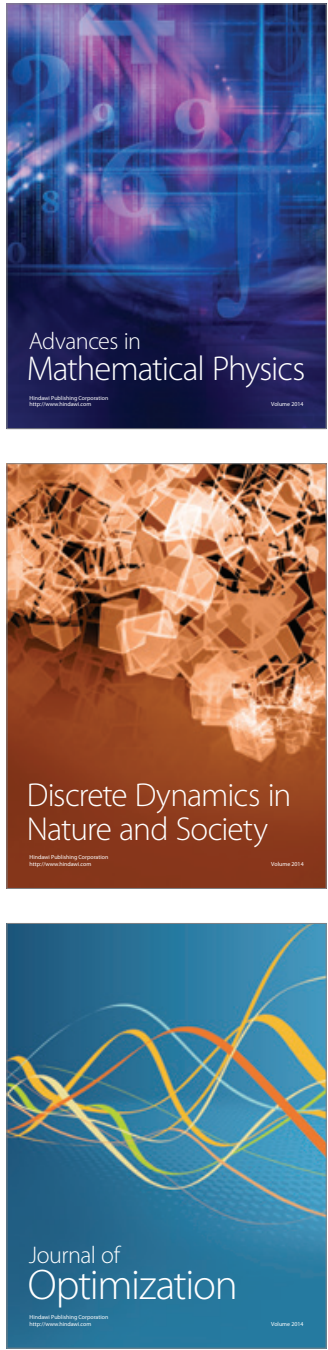